\title{
THE APRIL MEETING IN CINCINNATI
}

The six hundred sixty-fifth meeting of the American Mathematical Society was held at the Netherland Hilton Hotel, Cincinnati, Ohio, on Friday and Saturday, April 18-19, 1969. This meeting was originally scheduled for the Palmer House in Chicago. There were 296 registrants, including 251 members of the Society.

By invitation of the Committee to Select Hour Speakers for Western Sectional Meetings there were four one-hour addresses. Professor Edward R. Fadell of the University of Wisconsin spoke Friday morning on Recent developments in fixed-point theory. He was introduced by Professor Richard K. Lashof. Professor Pesi R. Masani of Indiana University addressed the Society on Friday afternoon, with Professor Laurence C. Young presiding. Professor Masani's subject was The role of vector and operator valued measures in functional analysis and probability. Professor William W. Boone of the University of Illinois, who was introduced by Professor H. David Lipsich, spoke Saturday morning. His talk was entitled The theory of decision problems in group theory: a survey. Professor François Treves of Purdue University addressed the Society on Saturday afternoon. His topic was On local solvability of linear partial differential equations; he was introduced by Professor Robert W. Carroll.

By invitation of the same committee there were two special sessions of selected twenty-minute papers. One of these, held Friday afternoon, was arranged by Professor Arunas L. Liulevicius of the University of Chicago on the subject of $K$-theory and Cohomology Operations; the speakers were Professors Peter Hoffman, Leif Kristensen, Peter S. Landweber, J. Peter May, and Mark E. Mahowald. The other special session, held Saturday afternoon, was on the subject of Algebraic Geometry and was arranged by Professor Maxwell A. Rosenlicht of the University of California, Berkeley, and Northwestern University; the speakers were Professors Shreeram Abhyankar, Satoshi Arima, David Hertzig, and Stephen S. Shatz.

There were eleven sessions of contributed ten-minute papers, including one added session not on the printed program. These sessions were chaired by Professor William W. Boone, Professor Robert W. Carroll, Professor Stefan Drobot, Professor Kent R. Fuller, Professor Richard J. Greechie, Professor J. G. Hocking, Professor Richard G. Larson, Professor Lee Lorch, Professor David Sachs, Dr. James W. Thatcher, and Professor James H. Wells. Of the 50 
ten-minute papers listed in the printed program, only 43 were actually presented. However, 9 late papers were added to the program giving a total of 52 contributed ten-minute papers.

Paul T. Bateman

Associate Secretary

URBANA, ILLINOIS 